\title{
Harmonic Elimination in Three-Phase Voltage Source Inverters by Particle Swarm Optimization
}

\author{
Mohamed Azab ${ }^{\dagger}$
}

\begin{abstract}
This paper presents accurate solutions for nonlinear transcendental equations of the selective harmonic elimination technique used in three-phase PWM inverters feeding the induction motor by particle swarm optimization (PSO). With the proposed approach, the required switching angles are computed efficiently to eliminate low order harmonics up to the $23^{\text {rd }}$ from the inverter voltage waveform, whereas the magnitude of the fundamental component is controlled to the desired value. A set of solutions and the evaluation of the proposed method are presented. The obtained results prove that the algorithm converges to a precise solution after several iterations. The salient contribution of the paper is the application of the particle swarm algorithm to attenuate successfully any undesired loworder harmonics from the inverter output voltage. The current paper demonstrates that the PSO is a promising approach to control the operation of a three-phase voltage source inverter with a selective harmonic elimination strategy to be applied in induction motor drives.
\end{abstract}

Keywords: Voltage source inverters, Harmonic elimination, Particle swarm optimization, Induction motor drives

\section{Introduction}

Selective harmonic elimination (SHE) is a well-known technique for generating PWM signals that can eliminate specific low-order harmonics from a voltage waveform generated by a voltage-source inverter (VSI). Although the method has long been established [1]-[3] and is reported in numerous papers, SHE is gaining new attention [4]-[12] due to the advancement in digital signal processing tools that permit the implementation of such algorithms. In addition, SHE is a viable alternative to other PWM techniques when the inverter frequency ratio is limited to a small value, as in the case of high-speed ac drives.

The main challenge associated with the SHE technique is how to obtain analytical solutions of the nonlinear transcendental equations that contain trigonometric terms [5]. Traditional analytical methods for solving the SHE problem are conducted based on the Newton Raphson method. The method requires proper initial values to converge to a proper solution. Moreover, it is based on differential information that will produce a local minimum solution leading to an undesirable PWM pattern.

In [8], and [9] complicated Walsh functions are utilized to solve the SHE problem, taking into consideration the concept of quarter wave symmetry. The method results in a set of algebraic matrix equations. The calculation of the optimal switching angles is a complex and time-consuming operation.

$\dagger$ Corresponding author: Dept. of Electrical Engineering Technology, High Institute of Technology, Benha University, Egypt. On leave to Yanbu Industrial College, EEET Department, Saudi Arabia. (pe_bhit@yahoo.com, mazab@yic.edu.sa)

Received: January 5, 2010; Accepted: December 29, 2010
Recently, non-traditional methods based on evolutionary algorithms, such as Genetic Algorithms (GA) [10], [11] and Ant Colony Systems (ACS) [12], have been employed for inverter harmonic elimination. These algorithms are shown to be superior to the calculus-based approach. In [11], the authors utilized GA to generate an optimal pulse pattern to suppress the 5 th and $7^{\text {th }}$ harmonics in a PWM inverter. In [12], the authors developed an algorithm for selective harmonic elimination based on the foraging behavior of a colony of ants. The authors reported that the convergence of ACS to the optimal solution is faster than that of GA.

In [13], the same author of this paper utilized the PSO to compute efficiently the switching angles of SHE in singlephase inverters only.

In the current paper, the PSO technique is employed for harmonic elimination in a three-phase VSI inverter feeding a squirrel cage induction motor. The proposed system is studied using Matlab, and its toolboxes (Simulink - Power system block set). The switching angles are obtained for the entire possible range of modulation index (between 0 and 0.9). To evaluate the proposed method, the THD and objective function are computed for different values of the amplitude modulation index. The harmonic spectra of the motor line-line voltage and current are also illustrated. The obtained simulation results prove that the method is efficient in removing the undesired low-order harmonics.

\section{Formulation of the SHE Problem}

The power circuit of a three-phase VSI is shown in Fig. 1. 
Under the SHE switching technique, the normalized phase voltage $\mathrm{V}_{\mathrm{a} 0}$ with respect to the fictitious dc center tap has a generalized waveform, as shown in Fig. 2. The output voltage is assumed to have nine pulses per half-cycle, with symmetrical switching angles around $\pi / 2$.

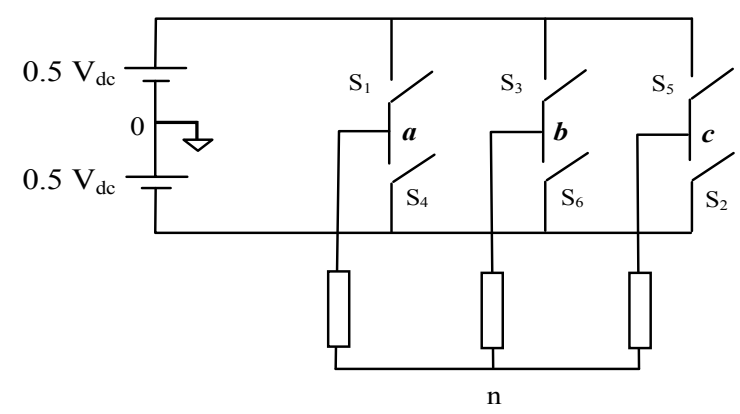

Fig. 1. Power circuit of a three-phase VSI.

If the waveform of Fig. 2 contains $(K+1)$ pulses per half cycle, $(K)$ harmonics can be controlled. In this case, study $K$ is equal to 8 .

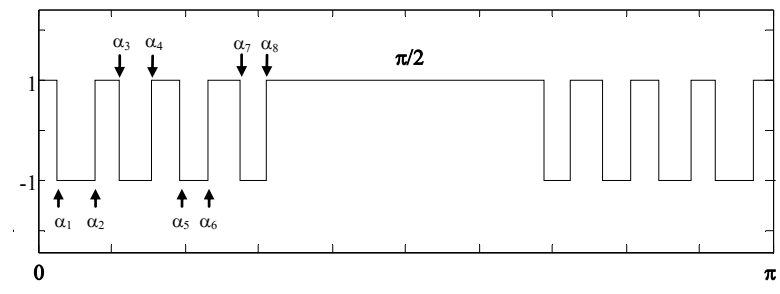

Fig. 2. Normalized inverter output voltage $V_{a}$.

The normalized voltage $\mathrm{V}_{\mathrm{a} 0}$ can be expressed as a Fourier series by Eq. (1):

$$
V_{a o}=\sum_{n=1}^{\infty} B_{n} \sin (n \omega t)
$$

where $\mathrm{n}$ has only odd values. The Fourier coefficients of the $\mathrm{V}_{\mathrm{a} 0}$ are computed by the following equation:

$$
B_{n}=\frac{4}{n \pi}\left[1+2 \sum_{i=1}^{K}(-1)^{i} \cos \left(n \alpha_{i}\right)\right]
$$

For $K=8$, Eq. (2) has 8 variables ( $\alpha_{1}$ to $\alpha_{8}$ ).

As the $3^{\text {rd }}$ harmonic and other triplen harmonics do not exist when the neutral point is isolated, $n$ takes the odd values $5,7,11,13,17,19$, and 23 .

Thus, the following equations should be solved simultaneously to obtain the proper switching angles.

To control the magnitude of the $1^{\text {st }}$ harmonic $(M \in[0,0.9])$ :

$$
\frac{4}{\pi}\left[\left(1+2 \sum_{i=1}^{8}(-1)^{i} \cos \left(\alpha_{i}\right)\right)-M\right]=0
$$

To eliminated the undesired low-order odd harmonics:

$$
\frac{4}{n \pi}\left[1+2 \sum_{i=1}^{8}(-1)^{i} \cos \left(n \alpha_{i}\right)\right]=0
$$

\section{Overview of PSO}

\subsection{Introduction}

PSO is a kind of evolutionary computation technique proposed by [16]. It is reliable in solving nonlinear problems with multiple optima. PSO is utilized for optimizing nonlinear functions based on the metaphor of the social behavior of a flock of birds searching for corn through social cooperation with the other birds around it (not by each individual). In PSO, each particle in a swarm represents a solution to the problem, and it is defined by its position and velocity [17]. The particles are placed in a search space of a certain problem or function. With each particle, an objective function is calculated at its current location. All of the particles have fitness values based on their position and velocities that direct the flight of the particles. PSO is initialized with a group of random particles (solutions), and then it searches for optima by updating generations.

In every iteration, each particle is updated by following two best values [18]. The first one is the best solution the particle has achieved so far called local best $(L)$. The second best value tracked by the algorithm is the best value obtained so far by any particle within the neighborhood called global best $(G)$. After determining the two best values, the particle updates its velocity and position with following equations:

$$
\begin{aligned}
& v_{i}(k+1)=w v_{i}(k)+c_{1} r_{1}\left[L_{i}(k)-x_{i}(k)\right]+c_{2} r_{2}\left[G(k)-x_{i}(k)\right] \\
& x_{i}(k+1)=x_{i}(k)+v_{i}(k+1)
\end{aligned}
$$

where $w$ is the inertia weight factor; $v_{i}(k)$ is the particle velocity at iteration $k ; x_{i}(k)$ is the particle position in the search space at iteration $k ; c_{1}$ and $c_{2}$ are positive constants called acceleration constants; and $r_{1}$ and $r_{2}$ are random numbers in between $(0,1)$.

Thus, the particles go through the problem space by following some simple rules.

\subsection{Steps of the PSO Algorithm}

The PSO algorithm has the following steps:

1. Random Initialization of PSO parameters

2. Computation of the objective function at the initial position

3. Updating the position and velocity using Eqs. 5 and 6

4. Evaluation of the updated position; the local best (L) and global best $(\mathrm{G})$ particles are updated.

5. Repeating the algorithms for the fixed number of itera- 
tions

6. Obtaining the best obtained values of $(\mathrm{G})$

3.3 Objective function to eliminate the harmonics $5^{\text {th }}$, $7^{\text {th }}, 11^{\text {th }}, 13^{\text {th }}, 17^{\text {th }}, 19^{\text {th }}$, and $23^{\text {rd }}$ and control the $1^{\text {st }}$

When the three-phase VSI inverter feeds a symmetrical load, the triplen harmonics do not exist. According to this information, the PSO is employed to eliminate the loworder odd harmonics $5^{\text {th }}, 7^{\text {th }}, 11^{\text {th }}, 13^{\text {th }}, 17^{\text {th }}, 19^{\text {th }}$, and $23^{\text {th }}$ from the waveform of the inverter output voltage for any desired value of the $1^{\text {st }}$ component in the permissible range $(M \leq$ 0.9 ). The following objective function should be minimized to obtain the solution:

$$
F=\operatorname{Min}\left\{\begin{array}{c}
\frac{16}{\pi^{2}}\left[\left(1+\sum_{i=1}^{8}(-1)^{i} \cos \left(\alpha_{i}\right)\right)-M\right]^{2}+ \\
{\left[\left(1+\sum_{i=1}^{8}(-1)^{i} \cos \left(n \alpha_{i}\right)\right) \frac{4}{n \pi}\right]^{2}}
\end{array}\right\}
$$

The objective function $F$ is subjected to the following constrain:

$$
0 \leq \alpha_{1} \leq \alpha_{2} \leq \alpha_{3} \leq \alpha_{4} \leq \alpha_{5} \leq \alpha_{6} \leq \alpha_{7} \leq \alpha_{8} \leq \pi / 2
$$

\section{Simulation Results}

The proposed PSO-based method is used to eliminate the low-order odd harmonics, $5^{\text {th }}, 7^{\text {th }}, 11^{\text {th }}, 13^{\text {th }}, 17^{\text {th }}, 19^{\text {th }}$, and $23^{\text {rd }}$ from the inverter voltage waveform for any desired value of the $1^{\text {st }}$ harmonic in the permissible range of modulation index $M$. In this section, the complete solution of switching angles is presented. All other presented results are registered for $M=0.5$ as a case study. Table 1 summarizes the parameters used in the PSO algorithm to solve the SHE problem.

Table 1. Parameters of the PSO algorithm.

\begin{tabular}{c|c}
\hline PSO parameter & Value \\
\hline Swarm size & 100 \\
\hline Maximum iterations & 100 \\
\hline Inertia weight factor & 0.9 \\
\hline
\end{tabular}

Table 2. Simulation parameters.

\begin{tabular}{c|c}
\hline Parameter & Value \\
\hline Input dc voltage $\mathrm{V}_{\mathrm{dc}}$ & $120 \mathrm{~V}$ \\
\hline Fundamental frequency & $50 \mathrm{~Hz}$ \\
\hline $\mathrm{R}_{\text {Load }}$ & $3 \times 1 \Omega$ \\
\hline $\mathrm{L}_{\text {Load }}$ & $3 \times 1 \mathrm{mH}$ \\
\hline
\end{tabular}

Table 2 presents the simulation parameters used with the three-phase VSI feeding a three-phase static inductive load.

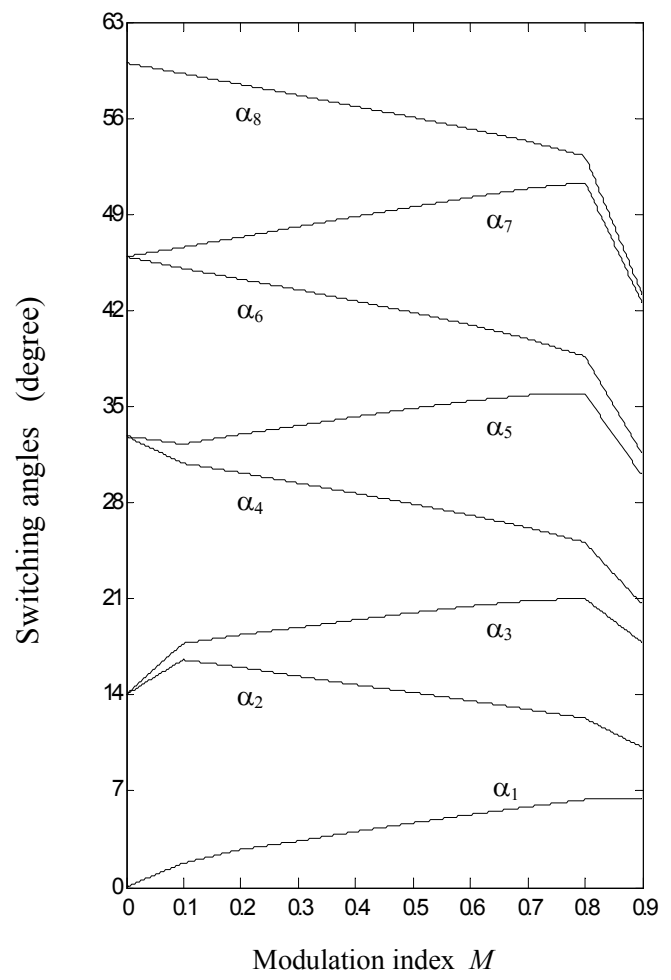

Fig. 3. PSO-based solution of switching angles: $\alpha_{1} \rightarrow \alpha_{8}$

In Fig. 3, the obtained PSO-based solution of the switching angles $\left(\alpha_{1} \rightarrow \alpha_{8}\right)$ of the SHE problem is presented for $M \in[0,0.9]$. As a sample case, the system is studied for $M$ $=0.5$.

The corresponding evolution of the objective function is plotted in Fig. 4. According to the obtained result, the PSO algorithm converged to the solution after 30 iterations.

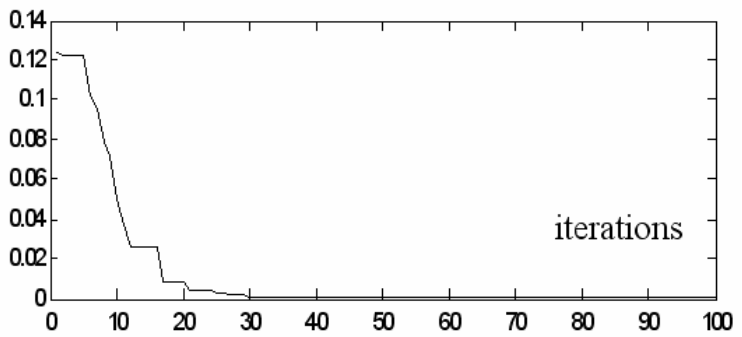

Fig. 4. Evolution of the objective function.

Table 3 illustrates the obtained set of solution for $M=$ 0.5. Moreover, the corresponding amplitudes of the loworder harmonics to be removed are computed. The results are presented in Table 4. According to the obtained results, the PSO method minimizes the objective function to a satisfactory value (1.76e-6). The low-order harmonics are well attenuated, and the amplitude of the $1^{\text {st }}$ harmonic is set to the desired value at the same time. 
Table 3. PSO-based computed switching angles to Eliminate the harmonics $5,7,11,13,15,19$, and 23 at $M=0.5$.

\begin{tabular}{c|c|c|c|c}
\hline$\alpha_{1}$ & $\alpha_{2}$ & $\alpha_{3}$ & $\alpha_{4}$ & $\alpha_{5}$ \\
\hline 4.68 & 14.20 & 19.99 & 27.92 & 34.86 \\
\hline \hline$\alpha_{6}$ & $\alpha_{7}$ & $\alpha_{8}$ & \multicolumn{2}{|c}{ obj-fun } \\
\hline 41.86 & 49.52 & 56.06 & \multicolumn{2}{|c}{$1.76 \mathrm{e}-06$} \\
\hline
\end{tabular}

Table 4. Corresponding magnitudes of the Fourier coefficients.

\begin{tabular}{c|c|c|c|c}
\hline Coeff. & $\mathrm{B}_{1}$ & $\mathrm{~B}_{5}$ & $\mathrm{~B}_{7}$ & $\mathrm{~B}_{11}$ \\
\hline desired & 0.5 & 0 & 0 & 0 \\
\hline actual & 0.5005 & $3.5 \mathrm{e}-04$ & $2.9 \mathrm{e}-04$ & $5.4 \mathrm{e}-04$ \\
\hline \hline Coeff. & $\mathrm{B}_{13}$ & $\mathrm{~B}_{17}$ & $\mathrm{~B}_{19}$ & $\mathrm{~B}_{23}$ \\
\hline desired & 0 & 0 & 0 & 0 \\
\hline actual & $4.7 \mathrm{e}-04$ & $6.9 \mathrm{e}-05$ & $2.7 \mathrm{e}-04$ & $8.6 \mathrm{e}-04$ \\
\hline
\end{tabular}

\subsection{Case Study I: Three-phase star connected (R-L) load}

The simulation parameters of the three-phase balanced R-L load are presented in Table 2. The generated control signals $\mathrm{S}_{1}, \mathrm{~S}_{3}$, and $\mathrm{S}_{5}$ of the upper transistors of the three-phase inverter bridge are plotted in Fig. 5 .

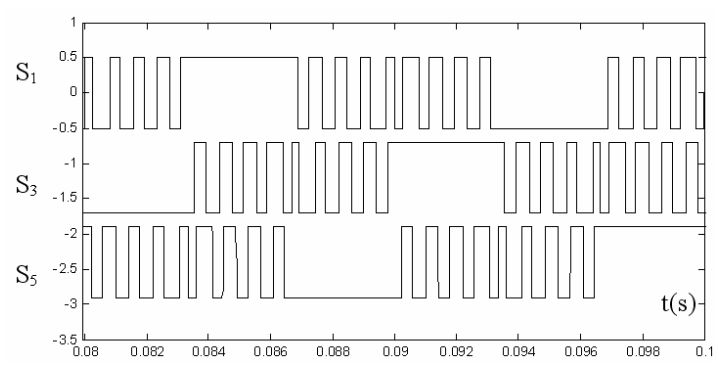

Fig. 5. Control signals: $\mathrm{S}_{1}, \mathrm{~S}_{3}$, and $\mathrm{S}_{5}$ at $M=0.5$.

The resultant inverter phase-neutral voltage $V_{\text {an }}$ is plotted in Fig. 6, whereas the line-line voltage $V_{a b}$ is illustrated in Fig. 7. To evaluate the performance of the proposed method, the harmonic spectrum of inverter phase-neutral voltage $\mathrm{V}_{\text {an }}$ is investigated. The results are plotted in Fig. 8 . According to the obtained results, the low-order harmonics up to 23 are well attenuated. The nearest component to the fundamental is the $25^{\text {th }}$ harmonic, which is not eliminated. The harmonic spectrum verifies the capability of the PSO algorithm to determine efficiently the required switching angles to implement the SHE strategy.

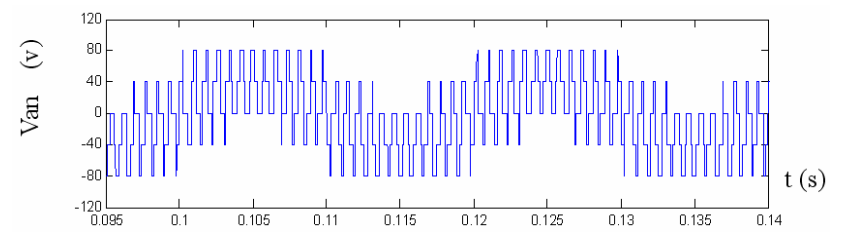

Fig. 6. Inverter phase-neutral voltage $\mathrm{V}_{\text {an }}(M=0.5)$.

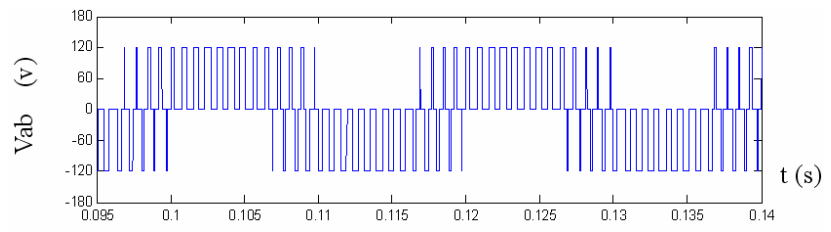

Fig. 7. Inverter line-line voltage $\mathrm{V}_{\mathrm{ab}}(\mathrm{M}=0.5)$.

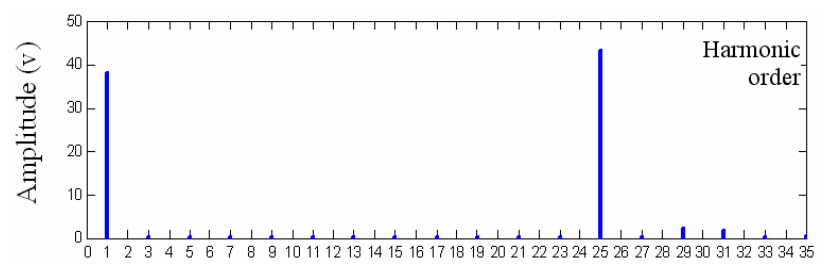

Fig. 8. Harmonic Spectrum of inverter voltage $V_{\text {an }}$

Moreover, the total harmonic distortion (THD) of the inverter phase-neutral voltage is computed for different values of the amplitude modulation index $(M)$ while eliminating the low-order harmonics up to the $23^{\text {rd }}$. The results are plotted in Fig. 9. The THD is defined as follows:

$$
T H D=\frac{\sqrt{V_{o r m s}^{2}-V_{1 r m s}^{2}}}{V_{1 r m s}}
$$

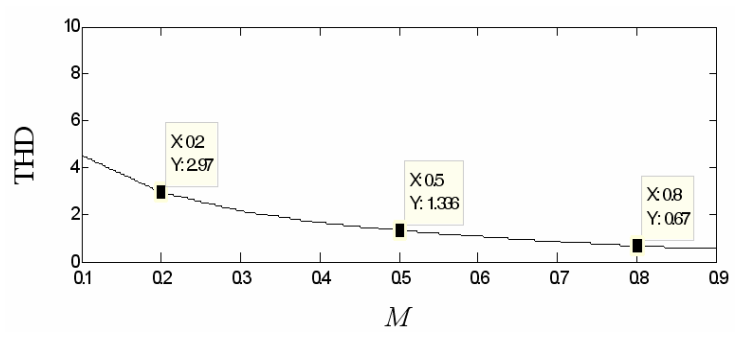

Fig. 9. THD of the inverter phase-neutral voltage $V_{\text {an }}$.

The three-phase inverter is loaded with a symmetrical star connected inductive load whose parameters are given in Table 2. The steady state three-phase load currents are shown in Fig 10. The corresponding harmonic spectrum is computed and plotted in Fig. 11.

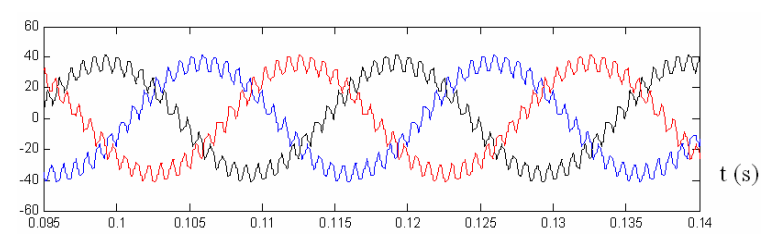

Fig. 10. Inverter load currents (inductive load).

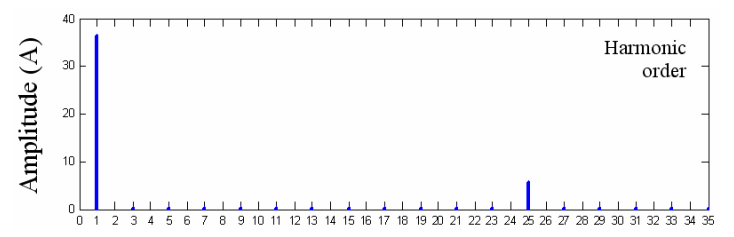

Fig. 11. Harmonic spectrum of the inverter load current $i_{a}$. 


\subsection{Case Study II: Three-phase star connected squir- rel cage induction motor (IM)}

In this section, the PSO-based solution is tested with a three-phase squirrel-cage induction motor drive with the following ratings: $4 \mathrm{~kW}, 400 \mathrm{~V} / 50 \mathrm{~Hz}$, and $1430 \mathrm{rpm}$. The parameters of the IM are indicated in Appendix 1, whereas the mathematical model of the squirrel IM is presented in Appendix 2.

The inverter dc input voltage is adjusted to $537 \mathrm{~V}$ as the output of three-phase uncontrolled bride rectifier fed from a three-phase ac supply of $380 \mathrm{~V} / 50 \mathrm{~Hz}$. The load torque is set to 10 N.m.

The overall system consists of a three-phase VSI-fed induction motor drive. The system is modeled and simulated using the Sim Power System under Matlab as a circuit based model.

In Fig. 12, the inverter phase-neutral voltage $\mathrm{V}_{\text {an }}$ is plotted for $M=0.5$ and fundamental frequency of $50 \mathrm{~Hz}$.

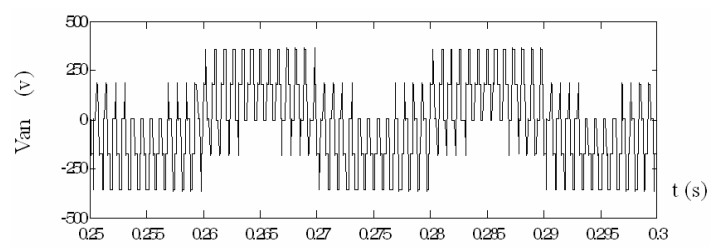

Fig. 12. Inverter phase-neutral voltage $\mathrm{V}_{\text {an }}(M=0.5)$.

The line-line voltage $V_{a b}$ is plotted in Fig. 13. To evaluate the performance of the proposed method, the harmonic spectrum of inverter line-line voltage $\mathrm{V}_{\mathrm{ab}}$ is investigated. The results are plotted in Fig. 14.

According to the obtained results, the low-order harmonics up to 23 are removed from the spectrum, proving the success of the proposed PSO solution. However, the $25^{\text {th }}$ harmonic component exists in the harmonic spectrum of inverter output voltage with relatively high magnitude compared with the fundamental.

The existence of such harmonic is not harmful in the case of the inductive load or in the ac motor drive considering the fact that the motor has a low-pass filter effect on the waveform of the current.

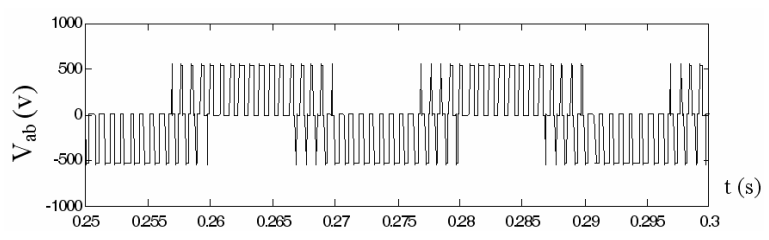

Fig. 13. Inverter line-line voltage $\mathrm{V}_{\mathrm{ab}}(M=0.5)$.

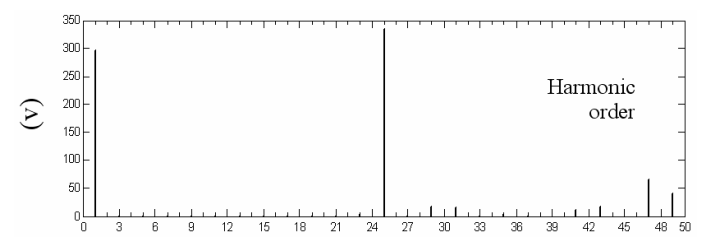

Fig. 14. Harmonic spectrum of the inverter line-line voltage
In addition, the THD of the inverter line-line voltage $\mathrm{V}_{\mathrm{ab}}$ under SHE technique is computed for different values of the modulation index $M$. The corresponding results are plotted in Fig. 15.

Under the same operating condition, the steady state ac motor currents drawn from the inverter are shown in Fig. 16. The corresponding harmonic spectrum of the phase current $i_{a}$ is plotted in Fig. 17. As shown in Fig. 17, the high-order harmonics $25^{\text {th }}, 47^{\text {th }}$, and $49^{\text {th }}$ are attenuated due to the low-pass filter nature of the motor to the current waveform.

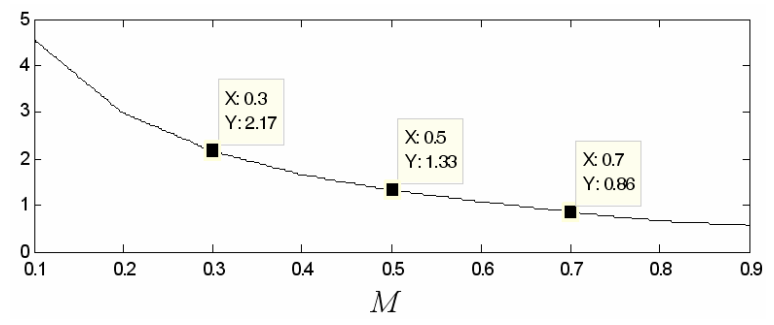

Fig. 15. THD of the inverter line-line voltage $V_{a b}$.

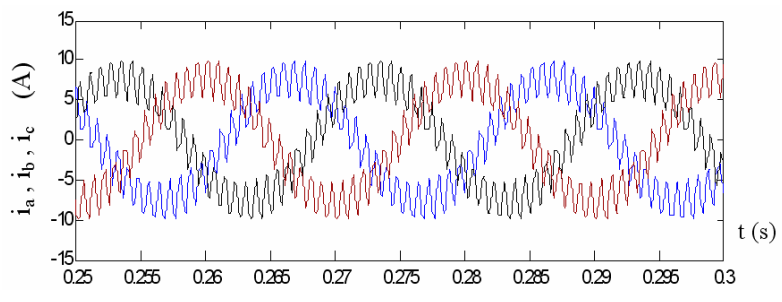

Fig. 16. Induction motor currents at the steady state.

The steady state stator flux locus is plotted in Fig. 18. The path is quasi circular due to the limited number of notches in the inverter voltage applied to the machine. In Fig. 19, the steady state waveform of the electromagnetic torque is presented.

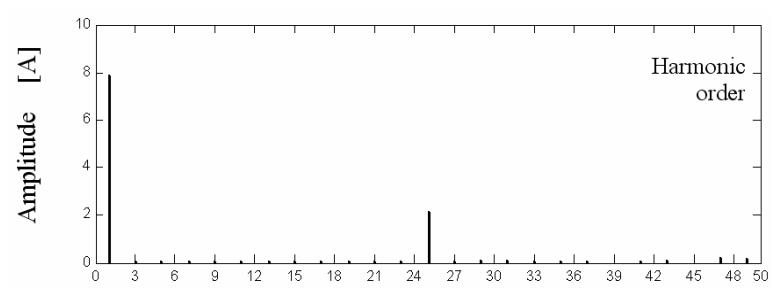

Fig. 17. Harmonic spectrum of the motor current $i_{a}$.

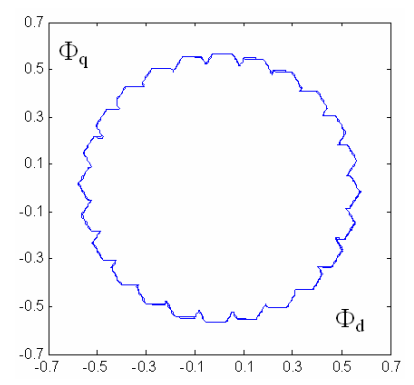

Fig. 18. Steady state of the stator flux locus [Wb]. 


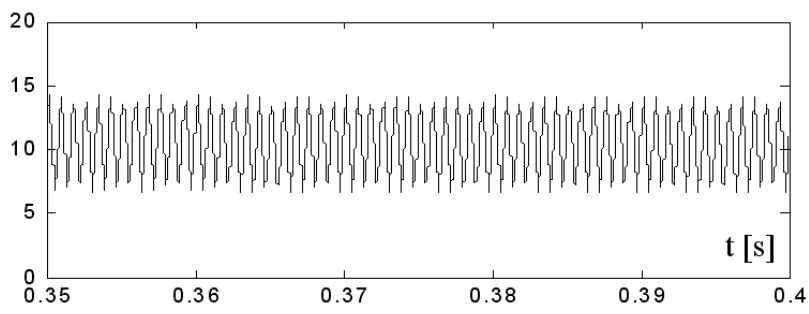

Fig. 19. Electromagnetic torque [N.m].
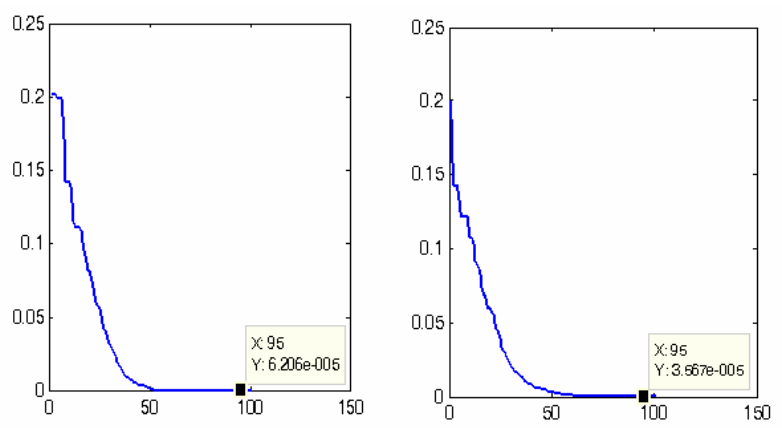

$M=0.1$

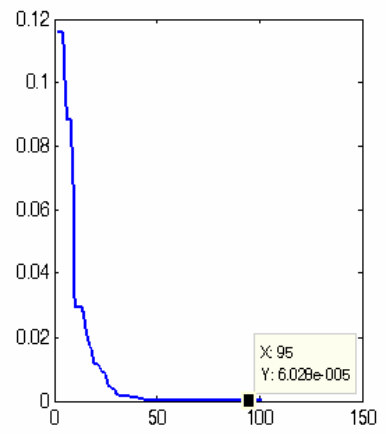

$M=0.4$

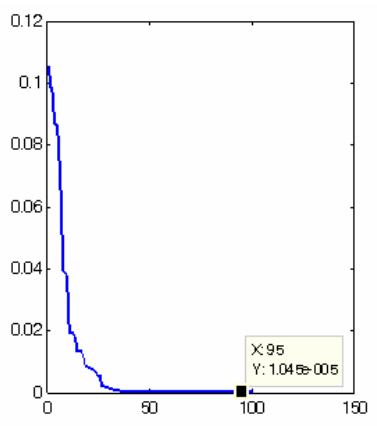

$M=0.7$
$M=0.2$

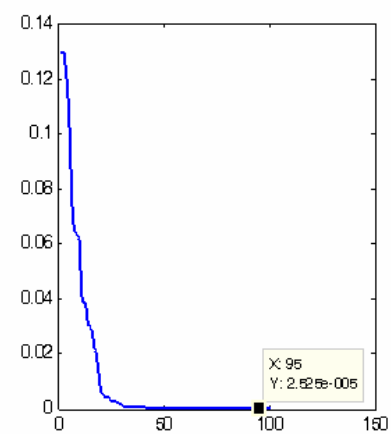

$M=0.6$

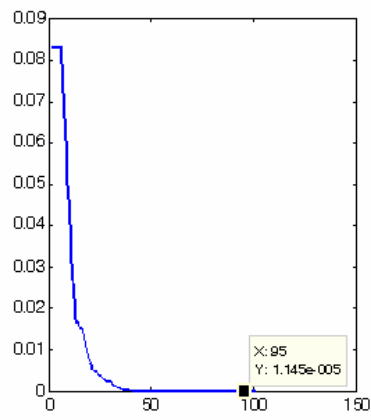

$M=0.8$

Fig. 20. Minimized objective function at different values of modulation index

The results of the stator flux components in the stationary reference frame and the electromagnetic torque are obtained based on the induction machine model mentioned in Appendix 2.

\subsection{Computation of the objective function at differ- ent values of the modulation index $M$}

To prove the excellent removing characteristics of the PSO technique in the low-order harmonics, the values of the objective function are computed for different values of the modulation index $(M)$. The corresponding simulation results of the instantaneous values of the objective function are presented in Fig. 20. The numerical values of the objective function after 95 iterations are indicated in Fig. 20. The results in Fig. 20 prove that the PSO technique succeeded in minimizing the objective functions for the entire range of the modulation index $M$.

As indicated in Fig. 20, the minimized objective function decreased to a very small value near zero. The worst observed value was $6.25 \mathrm{e}-5$, as shown in Fig. 20 for $M=0.4$. In addition, the algorithm of the PSO converges to the solution after several iterations, which do not exceed 65 iterations in the worst case.

\subsection{Computation of the harmonics at different values of the modulation index $M$}

The magnitude of the Fourier coefficients of the loworder harmonics of interest is computed at different values of the modulation index based on the solution of switching angles obtained from the PSO algorithm.

The system can be implemented by applying any one of the following techniques:

(1) Off-line solution of equations and computation of the switching angles

(2) Online computation

In the first approach, the PSO algorithm computes (offline) the required switching angles as a function of the desired fundamental component. The obtained results are stored in look-up-tables (LUT). The implementation of the method is easy and does not require special data acquisition cards. However, the accuracy of the method is determined by the size of the LUT. Extended LUTs can be used to consider many of the possible operating points.

In the second approach, a high-speed digital signal processor can be employed to carry out the PSO algorithm online.

\section{Conclusion}

In the current paper, the PSO-based algorithm is determined with a high-precision set of solutions of switching angles with a relatively high speed convergence.

PSO can be used successfully to control the operation of three-phase VSIs that feed induction motor drives. The fundamental component of the output voltage has the desired magnitude, eliminating several selected harmonics The results, which are formulated in Table 5, verify the capability of the PSO to solve the SHE problem. 
Table 5. Fourier coefficients of the harmonics based on the PSO solution

\begin{tabular}{|c|c|c|c|c|c|}
\hline Modulation index & $\mathrm{M}=0.1$ & 0.2 & 0.4 & 0.6 & 0.8 \\
\hline Desired $\mathrm{B}_{1}$ & 0.1 & 0.2 & 0.4 & 0.6 & 0.8 \\
\hline $\mathrm{B}_{1}$ & 0.1005 & 0.2006 & 0.4011 & 0.6002 & 0.8001 \\
\hline $\mathrm{B}_{5}$ & $1.8858 \mathrm{e}-004$ & $3.8468 \mathrm{e}-004$ & $7.9540 \mathrm{e}-004$ & $1.8032 \mathrm{e}-004$ & $4.2353 \mathrm{e}-004$ \\
\hline $\mathrm{B}_{7}$ & $1.3398 \mathrm{e}-004$ & 0.0016 & 0.0017 & $3.1519 \mathrm{e}-004$ & $3.6173 \mathrm{e}-004$ \\
\hline $\mathrm{B}_{11}$ & $6.9473 \mathrm{e}-004$ & 0.0011 & $2.8076 \mathrm{e}-004$ & $1.4754 \mathrm{e}-004$ & $2.9638 \mathrm{e}-004$ \\
\hline $\mathrm{B}_{13}$ & $1.1953 \mathrm{e}-004$ & $8.2488 \mathrm{e}-004$ & $7.3551 \mathrm{e}-006$ & $3.9734 \mathrm{e}-004$ & $2.9162 \mathrm{e}-005$ \\
\hline $\mathrm{B}_{17}$ & $1.0394 \mathrm{e}-004$ & 0.0011 & $9.1278 \mathrm{e}-004$ & $2.9330 \mathrm{e}-004$ & $2.1693 \mathrm{e}-004$ \\
\hline $\mathrm{B}_{23}$ & $4.9250 \mathrm{e}-004$ & $8.2745 \mathrm{e}-004$ & 0.0020 & $7.6596 \mathrm{e}-004$ & $7.8886 \mathrm{e}-004$ \\
\hline $\mathrm{B}_{25}$ & 0.1735 & 0.3282 & 0.5333 & 0.5385 & 0.3333 \\
\hline $\mathrm{B}_{29}$ & 0.0332 & 0.0633 & 0.0600 & 0.0303 & 0.1993 \\
\hline
\end{tabular}

\section{References}

[1] F. G. Turnbull, "Selected harmonic reduction in static dc-ac inverters," IEEE Trans. Commun. Electron., vol. 83, pp. 374-378, 1964.

[2] H. S. Patel and R. G. Hoft, "Generalized harmonic elimination and voltage control in thyristor inverters: Part I-harmonic elimination," IEEE Trans. Ind. Appl., vol. IA-9, no. 3, pp. 310-317, May/Jun. 1973.

[3] H. S. Patel and R. G. Hoft, "Generalized techniques of harmonic elimination and voltage control in thyristor inverters: part II-voltage control techniques," IEEE Trans. Ind. Appl., vol. IA-10, pp. 666-673, Sep/Oct 1974.

[4] J. R. Wells, et. al., "Modulation-Based Harmonic Elimination," IEEE Trans. Power Electron., vol. 22, no. 1, pp. 336-340, Jan 2007.

[5] V. G. Agelidis, et. al., "Multiple Sets of Solutions for Harmonic Elimination PWM Bipolar Waveforms: Analysis and Experimental Verification," IEEE Trans. Power Electron., vol. 21, no. 2, pp.415-421, March 2006.

[6] R. A. Jabr, "Solution trajectories of the harmonicelimination problem," Proc. Inst. Electr. Eng.Electric Power Applications, vol. 153, no. 1, pp. 97104, Jan. 1, 2006.

[7] J. N. Chiasson, et. al., "A complete solution to the harmonic elimination problem," IEEE Trans. Power Electron., vol. 19, no. 2, pp. 491-499, Mar. 2004.

[8] F. Swift and A. Kamberis, "A new Walsh domain technique of harmonic elimination and voltage control in pulse-width modulated inverters," IEEE Trans. Power Electron., vol. 8, no. 2, pp. 170-185, Apr. 1993.

[9] T.-J. Lang, et. al., "Inverter harmonic reduction using Walsh function harmonic elimination method," IEEE Trans. Power Electron., vol. 12, no. 6, pp. 971-982, Nov. 1997.

[10] A. I. Maswood, et. al., "A Flexible Way to Generate PWM-SHE Switching Pattern using Genetic Algorithm," IEEE Applied Power Electronics (APEC) Conf. Proc., Anaheim, California, USA, Vol. 2, 2001, pp. $1130-1134$.

[11] A. Sayyah, et. al., "Optimization of THD and Suppressing Certain Order Harmonics in PWM Inverters using Genetic Algorithms," Proc. of IEEE Interna- tional Symposium on Intelligent Control, Germany, Oct. 2006, pp. $874-879$.

[12] K. Sundareswaran, et. al., "Inverter Harmonic Elimination Through a Colony of Continuously Exploring Ants," IEEE Trans. Ind. Elect., vol. 54, no. 5, pp. 2558-2565, October 2007.

[13] Mohamed azab, "Particle Swarm Optimization-Based Solutions For Selective Harmonic Elimination In Single-Phase PWM Inverters", International Journal of Power electronics, Vol. 2, No. 2, 2010, Inderscience Enterprises Ltd- UK.

[14] M. Dorigo, et. al., "Ant system: Optimization by a colony of cooperation agents," IEEE Trans. Syst., Man, Cybern. B, Cybern., Vol. 26, no. 1, pp. 29-41, Feb. 1996.

[15] M. Dorigo, et. al., "Special section on ant colony optimization," IEEE Transactions on Evolutionary Computation, August 2002.

[16] J. Kennedy, R. Eberhart, "Particle Swarm Optimization," Proceedings of IEEE International Conference on Neural Networks (ICNN'95), Vol. IV, pp.19421948, 1995.

[17] Mohamed Azab, "Global maximum power point tracking for partially shaded PV arrays using particle swarm optimization", International Journal of Renewable Energy Technology, vol. 1, no. 2, pp. 211235, Inderscience Enterprises Ltd- UK, 2009.

[18] J. Hereford, M. Siebold, "Multi-robot search using a physically-embedded particle swarm optimization", International Journal of Computational Intelligence Research, Vol. 4, No. 2, pp.197-209, 2008.

\section{Appendix 1}

Parameters of the $4 \mathrm{~kW}$ Squirrel Cage IM

\begin{tabular}{c|c}
\hline Parameter & Value \\
\hline Stator resistance $\mathrm{R}_{\mathrm{S}}$ & $1.405 \Omega$ \\
\hline Stator leakage inductance $\mathrm{L}_{\mathrm{lS}}$ & $0.005839 \mathrm{H}$ \\
\hline Rotor resistance $\mathrm{R}_{\mathrm{r}^{\prime}}$ & $1.395 \Omega$ \\
\hline Rotor leakage inductance $\mathrm{L}_{\mathrm{lr}^{\prime}}$ & $0.005839 \mathrm{H}$ \\
\hline Mutual inductance $\mathrm{L}_{\mathrm{m}}$ & $0.1722 \mathrm{H}$ \\
\hline Inertia J & $0.0131 \mathrm{kgm}^{2}$ \\
\hline Friction factor $\mathrm{F}$ & $0.002985 \mathrm{~N} . \mathrm{m} . \mathrm{s}$ \\
\hline Pairs of pole $\mathrm{p}$ & 2 \\
\hline
\end{tabular}




\section{Appendix 2}

Mathematical model of the IM in the arbitrary reference frame

$$
\begin{aligned}
& V_{q s}=R_{S} i_{q s}+\frac{d}{d t} \varphi_{q s}+\omega \varphi_{d s} \\
& V_{d s}=R_{S} i_{d s}+\frac{d}{d t} \varphi_{d s}-\omega \varphi_{q s} \\
& V_{q r}^{\prime}=R_{r}^{\prime} i_{q r}^{\prime}+\frac{d}{d t} \varphi_{q r}^{\prime}+\left(\omega-\omega_{r}\right) \varphi_{d r}^{\prime} \\
& V_{d r}^{\prime}=R_{r}^{\prime} i_{d r}^{\prime}+\frac{d}{d t} \varphi_{d r}^{\prime}-\left(\omega-\omega_{r}\right) \varphi_{d r}^{\prime}
\end{aligned}
$$

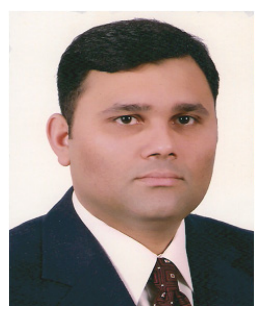

Dr. Mohamed Azab received his Ph.D. degree in electrical engineering in 2002 from the Polytechnic University of Catalonia (Universidad Politecnica de Catalunya-UPC), Barcelona, Spain. His research interests are switching power converters, renewable energy systems, and control of electric drives. Dr. Mohamed Azab is an Assistant Professor at the High Institute of Technology, Banha University, Egypt. Currently, he is on-leave to teach in Yanbu Industrial College, Saudi Arabia.

In the stationary reference frame $\omega=0$.

$$
\begin{aligned}
& V_{q s}=R_{S} i_{q s}+\frac{d}{d t} \varphi_{q s} \\
& V_{d s}=R_{S} i_{d s}+\frac{d}{d t} \varphi_{d s} \\
& V_{q r}^{\prime}=R_{r}^{\prime} i_{q r}^{\prime}+\frac{d}{d t} \varphi_{q r}^{\prime}-\omega_{r} \varphi_{d r}^{\prime} \\
& V_{d r}^{\prime}=R_{r}^{\prime} i_{d r}^{\prime}+\frac{d}{d t} \varphi_{d r}^{\prime}+\omega_{r} \varphi_{d r}^{\prime}
\end{aligned}
$$

Where

$$
\begin{aligned}
& \varphi_{q s}=L_{S} i_{q s}+L_{m} i^{\prime}{ }_{q r} \\
& \varphi_{d s}=L_{S} i_{d s}+L_{m} i_{d r}^{\prime} \\
& \varphi_{q r}^{\prime}=L_{r}^{\prime} i^{\prime}{ }_{q r}+L_{m} i_{q s} \\
& \varphi^{\prime}{ }_{d r}=L^{\prime}{ }_{r} i^{\prime}{ }_{d r}+L_{m} i_{d s} \\
& L_{S}=L_{l s}+L_{m} \\
& L_{r}^{\prime}=L_{l r}{ }_{r}+L_{m} \\
& T_{e}=1.5 p\left(\varphi_{d s} i_{q s}-\varphi_{q s} i_{d s}\right)
\end{aligned}
$$

